\title{
CDK-Taverna 2.0: migration and enhancements of an open-source pipelining solution
}

\author{
A Truszkowski ${ }^{1,3^{*}}$, S Neumann ${ }^{2}$, A Zielesny $^{3}$, E Willighagen $^{4}$, C Steinbeck \\ From 6th German Conference on Chemoinformatics, GCC 2010 \\ Goslar, Germany. 7-9 November 2010
}

Pipelining or workflow tools allow for the $\mathrm{Lego}^{\mathrm{TM}}$-like, graphical assembly of $\mathrm{I} / \mathrm{O}$ modules and algorithms into a complex workflow which can be easily deployed, modified and tested without the hassle of implementing it into a monolithic application.

The CDK-Taverna project aims at building an opensource pipelining solution through combination of different open-source projects such as Taverna [1], the Chemistry Development Kit (CDK) [2,3] or Bioclipse [4]. A first integrated version of CDK-Taverna was recently released to the public [5].

Current developments in CDK-Taverna refactor all workers as well as the complete setup on the basis of Taverna 2.2 and CDK 1.3.5 which themselves introduce major improvements to the whole platform. In addition the CDK is enhanced with specific functions and options for reaction enumeration based on a reaction template and corresponding reactant libraries. Reaction enumeration supports combinatorial chemistry approaches in the drug discovery process of the pharmaceutical industry. The CDK enhancements are applied and illustrated by corresponding CDK-Tavernaworkflows.
References

1. Oinn T, Addis M, Ferris J, Marvin D, Senger M, Greenwood M, Carver T, Glover K, Pocock MR, Wipat A, Li P: Taverna: a tool for the composition and enactment of bioinformatics workflows. Bioinformatics 2004, 20(17):3045-3054.

2. Steinbeck $C$, Han $Y Q$, Kuhn $S$, Horlacher O, Luttmann E, Willighagen E: The Chemistry Development Kit (CDK): An open-source Java library for chemo- and bioinformatics. J Chem Inf Comput Sci 2003, 43(2):493-500

3. Steinbeck C, Hoppe C, Kuhn S, Guha R, Willighagen EL: Recent Developments of The Chemistry Development Kit (CDK) - An OpenSource Java Library for Chemo- and Bioinformatics. Curr Pharm Design 2006, 12(17):2111-2120.

4. Spjuth O, Helmus T, Willighagen EL, Kuhn S, Eklund M, Steinbeck C, Wikberg JE: Bioclipse: An open rich client workbench for chemo- and bioinformatics. BMC Bioinformatics 2007, 8(59).

5. Kuhn T, Willighagen EL, Zielesny A, Steinbeck S: CDK-Taverna, an open workflow environment for cheminformatics. BMC Bioinformatics 2010, 11:159.

doi:10.1186/1758-2946-3-S1-P5

Cite this article as: Truszkowski et al:: CDK-Taverna 2.0: migration and enhancements of an open-source pipelining solution. Journal of Cheminformatics 2011 3(Suppl 1):P5.

\section{Author details}

${ }^{1}$ Chemoinformatics and Metabolism, European Bioinformatics Institute (EBI), Cambridge, UK. ${ }^{2}$ GNWI - Gesellschaft für naturwissenschaftliche Informatik $\mathrm{mbH}$, Oer-Erkenschwick, Germany. ${ }^{3}$ University of Applied Sciences of Gelsenkirchen, Institute for Bioinformatics and Chemoinformatics, Recklinghausen, Germany. ${ }^{4}$ Department of Pharmaceutical Biosciences, Uppsala University, Uppsala, Sweden.

Published: 19 April 2011

${ }^{1}$ Chemoinformatics and Metabolism, European Bioinformatics Institute (EBI), Cambridge, UK

Full list of author information is available at the end of the article

\section{Publish with ChemistryCentral and every scientist can read your work free of charge \\ "Open access provides opportunities to our colleagues in other parts of the globe, by allowing anyone to view the content free of charge." \\ W. Jeffery Hurst, The Hershey Company. \\ - available free of charge to the entire scientific community \\ - peer reviewed and published immediately upon acceptance \\ - cited in PubMed and archived on PubMed Central \\ - yours - you keep the copyright \\ Submit your manuscript here: \\ http://www.chemistrycentral.com/manuscript/

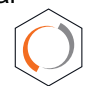 \\ ChemistryCentral}

